\title{
Developmental Changes in the Neurotransmitter Regulation of Correlated Spontaneous Retinal Activity
}

\author{
Wai T. Wong, Karen L. Myhr, Ethan D. Miller, and Rachel O. L. Wong \\ Department of Anatomy and Neurobiology, Washington University School of Medicine, St. Louis, Missouri 63110
}

Synchronized spontaneous rhythmic activity is a feature common to many parts of the developing nervous system. In the early visual system, before vision, developing circuits in the retina generate synchronized patterns of bursting activity that contain information useful for patterning connections between retinal ganglion cells and their central targets. However, how developing retinal circuits generate and regulate these spontaneous activity patterns is still incompletely understood. Here we show that in developing retinal circuits, the nature of excitatory neurotransmission driving correlated bursting activity in ganglion cells is not fixed but undergoes a developmental shift from cholinergic to glutamatergic transmission. In addition, we show that this shift occurs as presynaptic glutamatergic bipolar cells form functional connections onto the ganglion cells, implicating the role of bipolar cells in providing endogenous drive to bursting activity later in development. This transition coincides with the period when subsets of ganglion cells (On and Off cells) develop distinct activity patterns that are thought to underlie the refinement of their connectivity with their central targets. Here, our results suggest that the differences in activity patterns of On and Off ganglion cells may be conferred by differential synaptic drive from On and Off bipolar cells, respectively. Taken together, our results suggest that the regulation of patterned spontaneous activity by neurotransmitters undergoes systematic change as new cellular elements are added to developing circuits and also that these new elements can help specify distinct activity patterns appropriate for shaping connectivity patterns at later ages.

Key words: retinal development; ferret retina; spontaneous activity; retinal waves; activity dependent; APB; glutamate
Electrical activity in the developing nervous system is characterized by spontaneous periodic bursts of action potentials that are synchronized among neighboring cells (Feller, 1999; O’Donovan, 1999; Wong, 1999). Such activity occurs in the immature nervous systems of different species (Masland, 1977; Galli and Maffei, 1988; Meister et al., 1991; Gummer and Mark, 1994; Sernagor and Grzywacz, 1996; Wong et al., 1998; Zhou, 1998) and has been implicated in the development and refinement of neuronal connectivity (Katz and Shatz, 1996; Wong, 1999). Because of this functional importance, recent work has focused on how coordinated network oscillations are produced and regulated across development.

Spontaneous rhythmic activity in structures from the spinal cord to the hippocampus and retina often requires excitatory neurotransmission (O’Donovan, 1999). Intriguingly, spontaneous rhythmic activity occurs before and throughout the period when synaptic networks are assembled (Wong et al., 1993; Spitzer et al., 1995; Catsicas et al., 1998; Milner and Landmesser, 1999), raising the question of whether unique or even transient mechanisms are required for its production. Additionally, as new synaptic elements are incorporated across development, they may also exert regulatory influences that modify activity patterns in ways appropriate for establishing connectivity at each stage of development.

These questions can be studied readily in the retina because its

\footnotetext{
Received Aug. 4, 1999; revised Sept. 24, 1999; accepted Oct. 12, 1999.

This work was supported by the National Institutes of Health and the E. A. and J. Klingenstein Fund. We thank Chris Lee, Christian Lohmann, Bagirathy Nadarajah, and Rebecca Stacy for helpful comments and Dennis Oakley for technical assistance.

Correspondence should be addressed to Dr. Rachel O. L. Wong, Department of Anatomy and Neurobiology, Washington University School of Medicine, 660 South Euclid, St. Louis, MO 63110. E-mail address: wongr@thalamus.wustl.edu. Copyright (C) 1999 Society for Neuroscience $0270-6474 / 99 / 200351-10 \$ 15.00 / 0$
}

anatomy, circuitry, function, and development are well understood. Figure 1 schematically represents retinal circuits at two major phases of development in the ferret. In the first 2 postnatal weeks, retinal ganglion cells (RGCs) receive synaptic input from a lateral network of GABAergic and cholinergic amacrine cells. At this stage, RGCs undergo synchronized bursting activity in the form of propagating waves with all cells exhibiting a common bursting pattern. This activity is driven by cholinergic transmission (Feller et al., 1996; Penn et al., 1998) and modulated by GABAergic transmission (Fischer et al., 1998). Later, in the third and fourth week, the vertical pathway comprising glutamatergic bipolar and photoreceptor cells becomes assembled (Greiner and Weidman, 1981). Around this time, RGCs differentiate into On and Off subclasses with their dendritic arbors stratifying into different sublaminae in the inner plexiform layer (IPL) (Wong and Oakley, 1996; McCarthy et al., 1998) and their axonal terminals segregating into On and Off sublaminae in the dorsal lateral geniculate nucleus (Linden et al., 1981; Hahm et al., 1999). In addition, On and Off RGC populations begin to develop distinct bursting patterns. These contain cues that are appropriate for specifying the segregation of $\mathrm{On}$ and Off axonal arbors into separate thalamic sublaminae (Lee and Wong, 1996; Miller, 1996; Wong and Oakley, 1996).

In this study, we examined how the development of retinal circuits contributes to the regulation of spontaneous rhythms. We monitored spontaneous bursting in RGCs using calcium imaging and whole-cell recordings and determined pharmacologically at each stage the relative contributions from the lateral cholinergic and the vertical glutamatergic networks. We also examined the functional development of the bipolar circuitry in relation to its potential contribution to shaping differential On and Off activity patterns. 


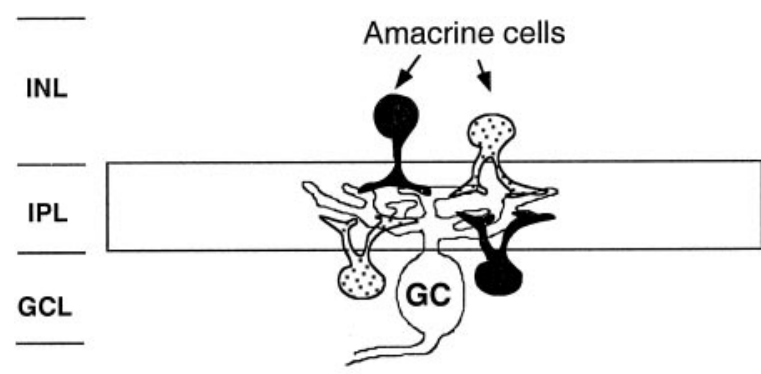

P20

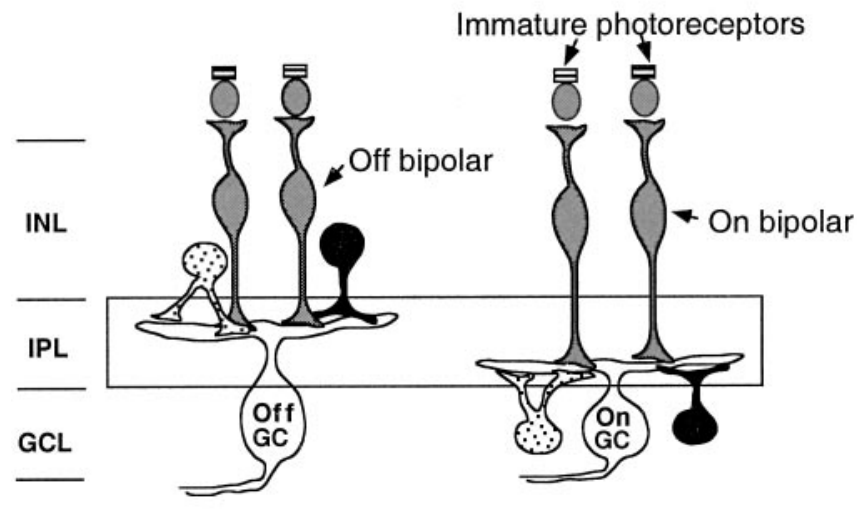

GABA

() ACh

Glutamate

Figure 1. Schematic drawing showing the nature of inputs to ferret RGCs at different stages in neonatal development before vision. Top, At P7, RGCs $(G C s)$ are known to receive mainly cholinergic $(A C h)$ and GABAergic input in the inner plexiform layer (IPL) from laterally projecting amacrine cells. (Cholinergic cells also colocalized GABA.) Amacrine cells may be conventional, with their somas in the inner nuclear layer $(I N L)$, or displaced, with their somas in the ganglion cell layer $(G C L)$. At this stage, ganglion cells often have their dendrites distributed throughout the width of the IPL. Bottom, Later in development, at P20, $G C s$ have differentiated into On and Off GCs and have stratified their dendrites within the IPL. They continue to receive input from the lateral network of amacrine cells, but in addition, they now receive glutamatergic input from a vertical network of bipolar interneurons, which are in turn postsynaptic to the photoreceptors. On ganglion cells receive input from On bipolars in the inner IPL, whereas Off ganglion cells receive input from Off bipolars in the outer IPL.

Parts of this paper have been published previously (Miller et al., 1998).

\section{MATERIALS AND METHODS}

Preparation of tissue. Ferret kits were obtained from Marshall Farms and used between the ages of postnatal day 7 (P7) and P23. The kits were deeply anesthetized with $5 \%$ halothane and quickly decapitated. The eyes were then enucleated, and the retinae were isolated from the eyecups in $4^{\circ} \mathrm{C}$, oxygenated Ringer's solution. The Ringer's solution contained (in mM): $128 \mathrm{NaCl}, 1 \mathrm{MgCl}_{2}, 5 \mathrm{KCl}, 2 \mathrm{CaCl}_{2}, 10 \mathrm{D}$-glucose, and $20 \mathrm{mM}$ HEPES (all reagents from Sigma, St. Louis, MO), pH 7.4. The retinae were floated onto a clean glass slide and held flat by a piece of black Millipore (Bedford, MA) filter paper as described previously (Wong and Oakley, 1996). To prepare retinal slices, we cut small pieces of retinae on the filter paper (150-200 $\mu \mathrm{m}$ thick) using a tissue chopper (Lukasiewicz and Roeder, 1995).

Calcium imaging. Calcium imaging was performed on retinal whole mounts maintained in oxygenated Ringer's solution at $35^{\circ} \mathrm{C}$. For P7-P8 retinae, cells in the ganglion cell layer were loaded with fura- 2 by incubating the tissue in $10 \mu \mathrm{M}$ fura- $2 \mathrm{AM}$ and $0.001 \%$ pluronic acid in
Ringer's solution for $30 \mathrm{~min}$ at room temperature and $30 \mathrm{~min}$ at $30^{\circ} \mathrm{C}$. In the older neonates, a preincubation step was introduced in which small slits were made in the peripheral retina and small drops of a concentrated solution of fura-2 AM in dimethylsulfoxide (DMSO; $50 \mu \mathrm{g}$ of indicator in $50 \mu \mathrm{l}$ of DMSO; $5-8 \mu \mathrm{l}$ of $2.5 \%$ pluronic acid in DMSO; all reagents from Molecular Probes, Eugene, OR) were placed above the slits using a Hamilton syringe (10 $\mu$ l capacity). Thereafter, the retinae were placed in the incubation solution as described for the P7-P8 retinae. These loading techniques have been described in detail elsewhere (Baldridge, 1996; Wong and Oakley, 1996).

Bursting activity was recorded by monitoring ratiometric changes in fluorescence intensity at 340 and $380 \mathrm{~nm}$ excitation. Images were acquired using a filter wheel, shutter assembly (Sutter Instruments), and an SIT camera (Hamamatsu) under computer control (Image-1FL; Universal Imaging Corporation, West Chester, PA). Images were captured every $2.8 \mathrm{sec}$, and the analysis was performed off-line using Image-1FL. Estimated intracellular calcium levels $\left(\left[\mathrm{Ca}^{2+}\right]_{\mathrm{i}}\right)$ were obtained by conversion of the ratios to $\left[\mathrm{Ca}^{2+}\right]_{\mathrm{i}}$ based on a calibration curve obtained before the experiment (Wong et al., 1995; Wong and Oakley, 1996).

Whole-cell recordings. For electrical recordings, retinal slices or whole mounts were used. The tissue was maintained at $32^{\circ} \mathrm{C}$ in oxygenated Ringer's solution. For whole-mount recordings, Muller end-feet covering the cell bodies in the ganglion cell layer were mechanically cleared before patching. For both slices and whole mounts, debris covering the ganglion cell somas was removed by gentle suction with a patch pipette with an enlarged tip.

Gigaohm seals were formed onto ganglion cells with a new pipette containing (in mM): 133 cesium gluconate, 10 TEA chloride, $0.4 \mathrm{MgCl}_{2}$, $10 \mathrm{NaCl}$, and 7 sodium HEPES, with $0.02-0.04 \%$ Lucifer yellow. The whole-cell configuration was achieved by suction and buzzing (Axopatch 200B). Liquid junction potentials were compensated before sealing onto cells with the pipette offset $(-14.5 \mathrm{mV})$. Cells were held in voltage-clamp mode at the reversal potential for chloride-mediated currents to isolate glutamate- and acetylcholine-mediated (cationic) currents. The chloride reversal potential was determined to be $-55 \mathrm{mV}$, as assessed by plotting the $I-V$ relationship of the cell's response to puffs of glycine. This value was close to the calculated value of $-62 \mathrm{mV}$. Continuous recordings of spontaneous activity (at least 4 min for old retinas and at least 8 min for young retinas) were saved onto a DAT recorder (DAS75; Dagan).

Data were analyzed off-line with a program written in MatLab after being downloaded at 10 or $11 \mathrm{kHz}$. Drug effects were measured by comparing the charge transferred per minute in the absence and presence of antagonists. Charge transferred was calculated as the area under the current trace above the baseline. The average charge transfer per minute was calculated as the total charge transferred divided by the duration of the recording (in minutes). This provided a comparison of the mean activity level of the cells.

Pharmacology. For both calcium imaging and whole-cell recordings, antagonists to ionotropic glutamate and cholinergic receptors were bath applied after a baseline recording of the bursting activity was obtained. Each recording involving the application of drugs was performed on a separate piece of retina. Ionotropic glutamate antagonists used include 1,2,3,4-tetrahydro-6-nitro-2,3-dioxo-benzo(f)quinozaline-7-sulfonamide (NBQX; Research Biochemicals, Natick, MA), a selective AMPA/kainate receptor antagonist, and 2-amino-5-phosphonopentanoic acid (DAPV; Precision, Vancouver, British Columbia, Canada; D,L-APV; Research Biochemicals), a selective NMDA receptor antagonist. Selective blockade of $\mathrm{GABA}_{\mathrm{A}}$ receptors was achieved with bicuculline (Research Biochemicals), and blockade of glycinergic receptors was achieved with strychnine (Sigma). Activation of the metabotropic glutamate receptor mGluR6 was achieved with D,L-2-amino-4-phosphonobutyric acid (APB; Calbiochem, La Jolla, CA). Cholinergic antagonists used were dihydrobetaerythrodine (DH $\beta$ E; Sigma), a competitive nicotinic receptor antagonist (Rapier et al., 1990), and D-tubocurarine chloride (curare; Sigma), a general nicotinic cholinergic blocker. Because antagonists may be less selective in the younger ages, we used a third neuronal nicotinic receptor antagonist, mecamylamine (Sigma), that acts as a noncompetitive blocker, binding primarily to the open channel configuration of the nicotinic receptor (Varanda et al., 1985). The apparent drop in baseline $\left[\mathrm{Ca}^{2+}\right]_{\mathrm{i}}$ after the addition of bicuculline arises from the differential absorption of UV light by the antagonist as assessed in Fischer et al. (1998) and does not represent a real reduction of baseline intracellular calcium levels. Spontaneous calcium elevations (calcium peaks) were scored similarly on this declining baseline.

The doses of antagonists used in the study were those that have been 
demonstrated previously to block evoked responses by the application of the relevant agonists (Wong, 1995a,b; Fischer et al., 1998). Similar doses have also been used to block specific modes of neurotransmission in other spontaneously active systems (Roerig et al., 1997; Chub and O'Donovan, 1998; Garaschuk et al., 1998; Schwartz et al., 1998; Milner and Landmesser, 1999).

\section{RESULTS}

\section{Contribution of cholinergic transmission to spontaneous activity across development}

Rhythmic bursting activity in the ganglion cells is characterized by periodic increases in $\left[\mathrm{Ca}^{2+}\right]_{\mathrm{i}}$ (Fig. 2). Calcium imaging of whole-mounted retinae reveals that early in development (P7P8), blockade of nicotinic cholinergic transmission by the bath application of the antagonist $\mathrm{DH} \beta \mathrm{E}$ resulted in a significant decrease in the bursting rates in RGCs (Fig. 2A). By contrast, the same drug application in older retinae (P20-P23) did not reduce the rate of bursting activity (Fig. $2 B$ ). Quantification of the results shows that although $\mathrm{DH} \beta \mathrm{E}$ suppressed the mean bursting rate of ganglion cells in the younger retinae to $66.1 \pm 2.1 \%$ ( \pm SEM) of the baseline rate, it failed to suppress bursting activity in the older retinae, even appearing to increase it slightly to $111.1 \pm 2.5 \%$ of baseline rates (Fig. 2C). This may be an indirect effect arising from a small degree of excitatory cholinergic drive onto inhibitory GABAergic or glycinergic neurons that are known in the later ages to suppress spontaneous bursting in ganglion cells (Fischer et al., 1998). The changing effect of cholinergic blockade was also observed with the other antagonists used. In younger retinae, mecamylamine reduced bursting to a comparable $69.9 \pm 2.4 \%$ of the baseline rate, whereas curare, a commonly used antagonist, had a larger effect and abolished activity altogether $(0 \pm 0 \%)$ in all cells (Fig. 2C). In marked contrast, even curare failed to decrease bursting frequency in the older retinae $(97.3 \pm 5.2 \%)$. These results indicate that although excitatory nicotinic cholinergic transmission is important in driving correlated bursting activity early on, its contribution diminishes later in development.

\section{Contribution of glutamatergic transmission to spontaneous activity across development}

To assess the contribution of glutamatergic transmission across the same period of development, we monitored spontaneous bursting activity in the absence and presence of antagonists to ionotropic glutamate receptors at the two age groups using calcium imaging. At P7-P8, applications of APV and NBQX separately decreased bursting rates by a small amount; the combined application of both antagonists decreased the bursting rate to a greater extent but did not eliminate bursting activity entirely (Fig. 3 ). In older retinae, at P20-P23, separate applications of NBQX and APV in each case reduced the bursting rate more effectively than in the younger retina, but bursting activity was similarly not eliminated (Fig. 4). However, the combined application of both NBQX and APV abolished bursting activity completely.

Previous experiments have demonstrated that the spontaneous intracellular calcium elevations in ganglion cells correspond to bursts of action potentials measured by electrophysiology (Penn et al., 1998; Wong et al., 1998). To confirm that the application of NBQX and APV abolished activity by blocking neurotransmission, we performed whole-cell patch recordings of ganglion cells in the absence and presence of these antagonists. Under voltage clamp at the reversal potential for $\mathrm{Cl}^{-}$, periodically occurring postsynaptic currents (PSCs) were observed for both age groups (Fig. 5). Although the combined addition of NBQX and APV to younger retinae did not eliminate these currents, the same drug
A

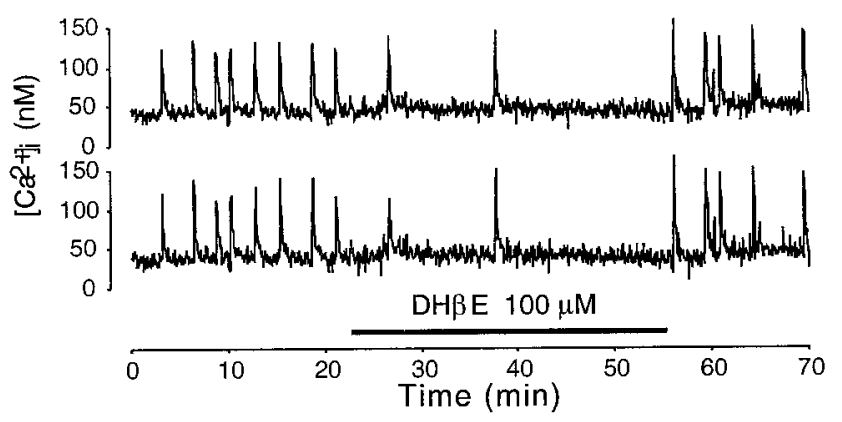

B
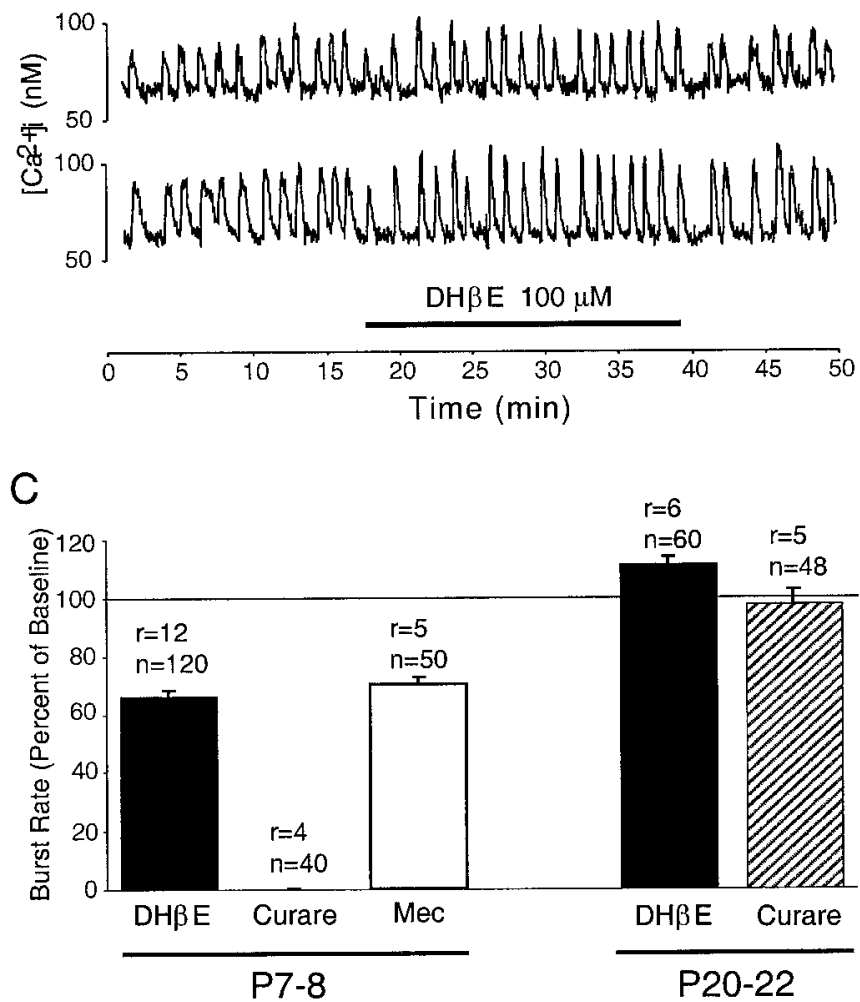

Figure 2. Changing dependence of spontaneous bursting activity in RGCs on cholinergic transmission as evaluated with calcium imaging in the ganglion cell layer. $A, B$, Examples of the effect of $\mathrm{DH} \beta \mathrm{E}$, a nicotinic cholinergic antagonist, on the bursting activity of cells at P8 $(A)$ and P20 $(B)$ (duration of drug application is denoted by horizontal bar). C, Quantitative summary of the effects of cholinergic blockade with various antagonists on the rate of spontaneous bursting at P7-P8 and P20-P22. Burst rates in the various cholinergic antagonists are expressed as a percentage of the rate under control conditions (Ringer's solution) immediately preceding the bath application of the drug. Effects of drugs at each age were significant, except for curare at P20-P22 (Mann-Whitney test, $p<0.001)$. The concentrations of drugs used were 100-200 $\mu \mathrm{M}$ (DH $\beta \mathrm{E}), 20-50 \mu \mathrm{M}$ (curare), and 80-160 $\mu \mathrm{M}$ [mecamylamine $(\mathrm{Mec})](r=$ number of recordings; $n=$ number of cells monitored).

application in older retinae abolished all spontaneous PSCs. Thus, the absence of periodic spontaneous calcium elevations in the presence of NBQX and APV arises from the blockade of spontaneous cationic currents.

Quantification of the results from calcium imaging and voltageclamp recordings are summarized in Figure 6. In younger P7-P8 retinae, NBQX and APV each reduced mean bursting rates by 

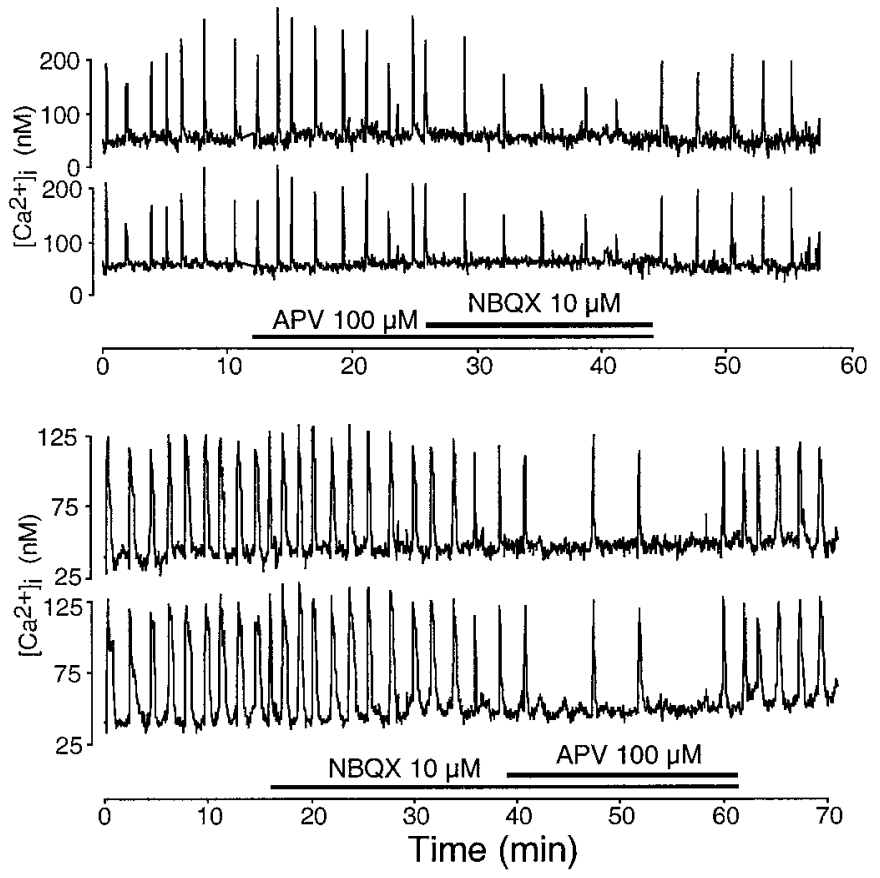

Figure 3. Effect of ionotropic glutamatergic blockade on the bursting activity of representative cells in P7-P8 retinae as evaluated by calcium imaging. Each trace plots the variations in somatic $\left[\mathrm{Ca}^{2+}\right]_{\mathrm{i}}$ over time. The durations of drug applications are denoted by the horizontal bars.

P20-21
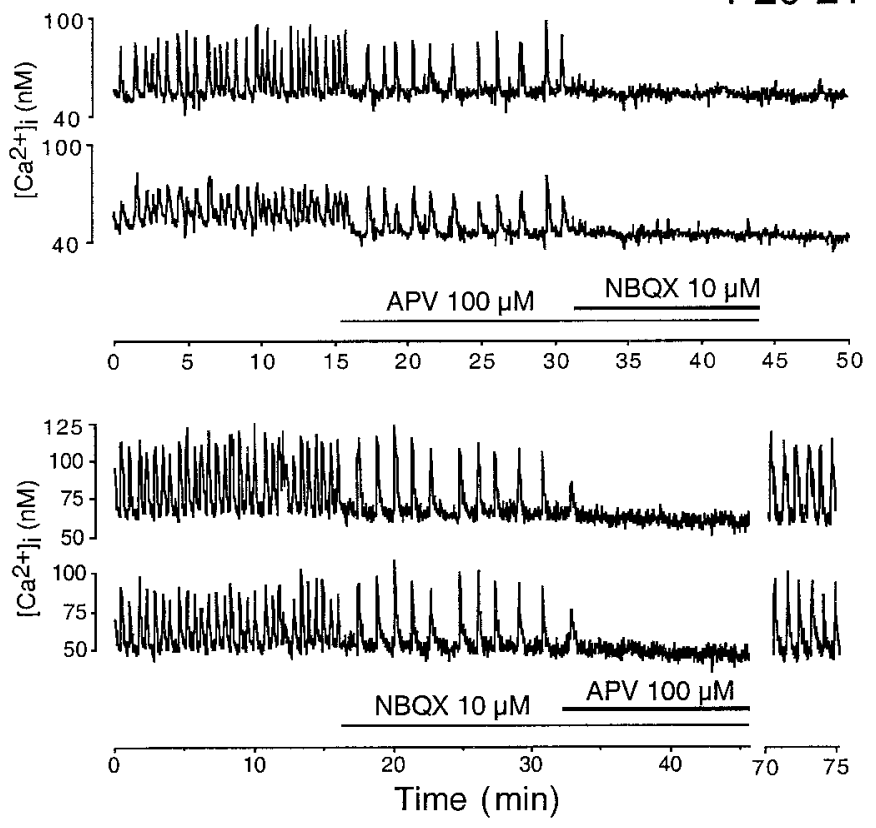

Figure 4. Effect of ionotropic glutamatergic blockade on the bursting activity of representative cells in P20-P21 retinae as monitored by calcium imaging. The durations of drug applications are denoted by the horizontal bars.

similar amounts $(81.4 \pm 2.9$ and $82.1 \pm 1.9 \%$ respectively $)$, whereas the combination of the antagonists decreased bursting to $55.9 \pm 1.2 \%$ of the baseline (Fig. $6 A$ ). Addition of $\mathrm{DH} \beta \mathrm{E}$ to NBQX and APV further reduced bursting activity to $28.7 \pm$

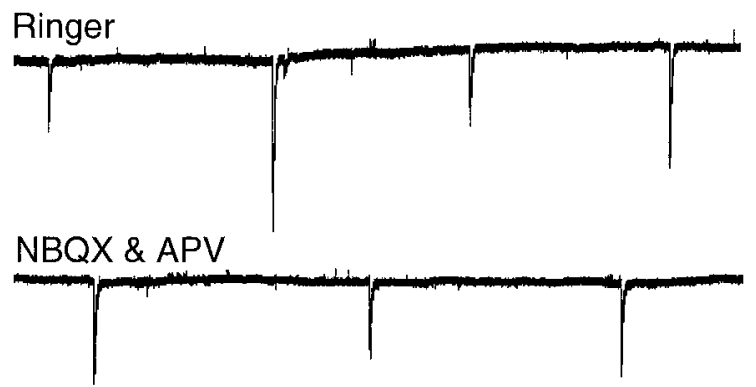

Washout

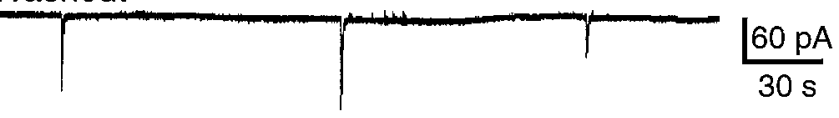

P23

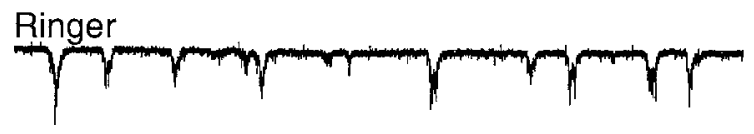

NBQX \& APV

Washout

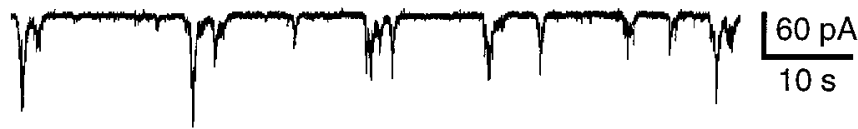

Figure 5. Development of the dependence of postsynaptic currents on glutamatergic input. Ganglion cells were voltage clamped at the reversal potential for $\mathrm{Cl}^{-}$. Top (P8), The glutamate receptor antagonists did not block the periodic postsynaptic potentials. Bottom (P23), Top Trace, A recording from a representative ganglion cell shows the more complex older bursting pattern. Middle Trace, This record is an example of the glutamate receptor antagonists completely eliminating all postsynaptic potentials. Bottom Trace, The potentials returned within 8 min of washing out the antagonists.

$1.3 \%$ of baseline rates (Fig. $6 A$ ). This suggests that for this early age group, both acetylcholine and glutamate contribute to spontaneous bursting activity of the ganglion cells and that the excitatory drives mediated via cholinergic, glutamatergic AMPA/ kainate receptors and glutamatergic NMDA receptors are additive in nature. In older $\mathrm{P} 20-\mathrm{P} 23$ retinae, NBQX alone decreased mean bursting rates to $42.6 \pm 1.8 \%$, whereas APV alone reduced mean bursting rates to $74.9 \pm 2.6 \%$, suggesting that at the older ages, the excitatory drive to spontaneous bursting as mediated via AMPA/kainate receptors is larger than that mediated via NMDA receptors. When NBQX and APV are applied together, the bursting rate in older retinae was reduced to $1.1 \pm$ $0.4 \%$ of baseline values. This trend is also corroborated by measurements of charge transfer for the postsynaptic currents in patch-clamp recordings; when NBQX and APV were applied together to younger P7-P8 retinae, the average charge transfer per minute decreased to $63 \pm 9 \%$ of baseline values. In contrast, the same application to older P20-P23 retinae had a much larger effect, reducing the average charge transfer per minute more markedly to $5 \pm 1 \%$ of baseline values (Fig. $6 B$ ). 
A

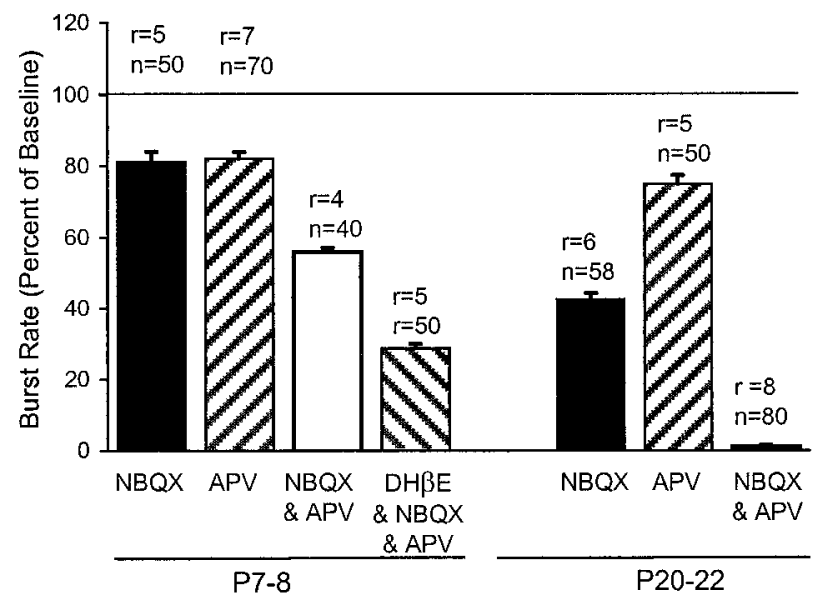

B

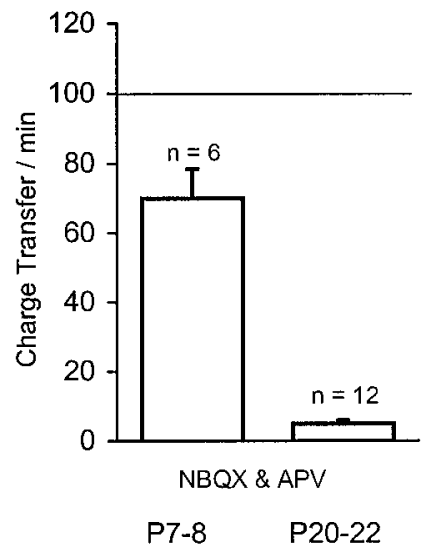

Figure 6. Quantitative summary of the effects of ionotropic glutamatergic blockade on spontaneous bursting activity at P7-P8 and P20-P22. A, From calcium recordings, burst rates in the presence of various antagonists are expressed as a percentage of the rate under control conditions (Ringer's solution) preceding the bath application of the antagonists. Drug concentrations applied were $10 \mu \mathrm{M}(\mathrm{NBQX}), 100 \mu \mathrm{M}$ (D-APV), and $100 \mu \mathrm{M}$ (DH $\beta$ E). All effects were significant (Mann-Whitney test, $p<0.001 ; r=$ number of recordings; $n=$ number of cells monitored). $B$, From voltage-clamp recordings, the charge transfer per minute in the presence of NBQX $(10 \mu \mathrm{M})$ and D-APV $(100 \mu \mathrm{M})$ is expressed as the percentage of the charge transfer per minute in Ringer's solution preceding the bath application of the antagonists. The antagonists decreased the charge transfer per minute somewhat for cells from P7 to P8 $(n=6 ; p=0.0640$, Student's $t$ test, paired two-tail), whereas they eliminated nearly all charge transfer for cells from P20 to P24 $(n=12 ; p=$ 0.0002 , Student's $t$ test, paired two-tail).

Collectively, these results show that, contrary to the developmental trend observed with cholinergic transmission, the contribution of excitatory glutamatergic transmission to spontaneous bursting activity increases across development and becomes essential to bursting activity per se in older neonates. This requirement for glutamatergic transmission is absolute even in the absence of inhibitory drive from GABAergic and glycinergic amacrine cells. The combination of NBQX and APV continues to suppress all bursting activity even in the presence of antagonists to GABAergic (bicuculline, $150 \mu \mathrm{M}$ ) and glycinergic (strychnine, $1-5 \mu \mathrm{M})$ transmission, as assessed by calcium imaging in whole-mount retina (data not shown).

\section{Maturation of functional connections between bipolar interneurons and ganglion cells}

Our results thus far indicate that spontaneous activity in the ganglion cells becomes totally dependent on glutamatergic transmission as the glutamatergic bipolar interneurons mature and make synaptic contact onto ganglion cells. However, the maturation of the bipolar cell circuitry has thus far been inferred only from anatomical observations (Greiner and Weidman, 1981). To implicate bipolar cells further as a source of transmission driving spontaneous activity in ganglion cells in the older neonates, we examined the time at which bipolar cells make functional glutamatergic connections onto ganglion cells. We assayed for the presence of bipolar-to-ganglion cell connections at different ages by stimulating the dendrites of bipolar cells in the outer plexiform layer and measuring evoked responses in cells in the ganglion cell layer (Fig. 7). This experiment was performed in retinal slices in which puffs of potassium chloride were delivered to the outer plexiform layer via a patch pipette during calcium imaging. The presence of a functional drive from bipolar cells was indicated by the ability to evoke repeatedly a rise in $\left[\mathrm{Ca}^{2+}\right]_{\mathrm{i}}$ in the surrounding ganglion cells and amacrine cells. Because our previous anatomical analysis of the development of bipolar cells suggests the presence of morphologically differentiated bipolar cells by P10-

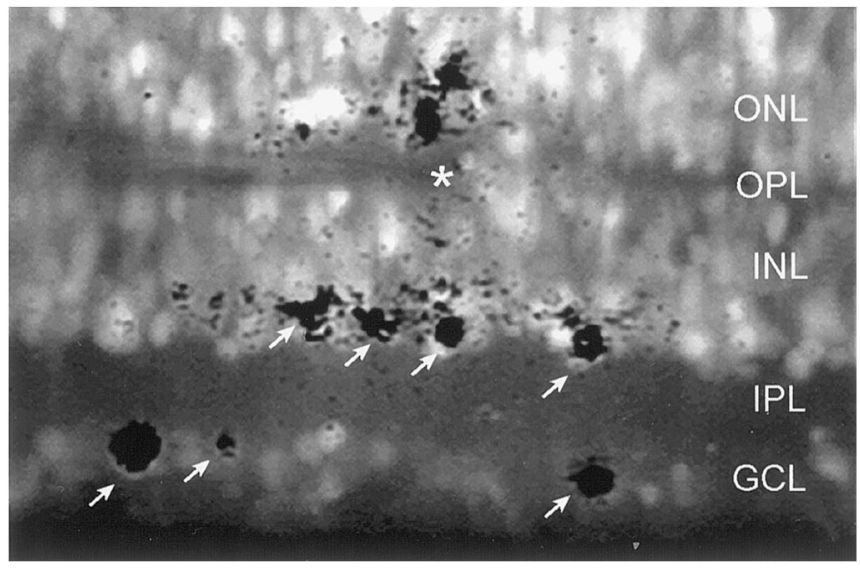

Figure 7. Experimental setup for detecting functional bipolar-toganglion cell connections. View of a fura-2-loaded P21 retinal slice under $380 \mathrm{~nm}$ illumination. The tip of a $\mathrm{K}^{+}$-filled patch pipette (asterisk) was positioned at the outer plexiform layer $(O P L)$. A single puff $(10 \mathrm{msec} ; 10$ psi) evoked a rise in $\left[\mathrm{Ca}^{2+}\right]_{\mathrm{i}}$ in many cells (shown by the overlay of dark profiles) in this field. The regions of elevated $\left[\mathrm{Ca}^{2+}\right]_{\mathrm{i}}$ were revealed by digital subtraction of images (each image was a 16 frame average) preceding and immediately after the puff. The subtracted image was then overlaid digitally with a background image (average of 3 images) to produce the composite image shown here. Arrows indicate cells that responded to the puff, most likely because of activation of bipolar cells with dendrites in the $O P L$; regions near the pipette tip were likely to be stimulated directly. $G C L$, Ganglion cell layer; $I N L$, inner nuclear layer; $O N L$, outer nuclear layer.

P11 (Miller et al., 1999), we stimulated retinal slices from P11 to P21 animals. Intracellular calcium responses were evaluated in multiple cells in each retinal slice recording; the number of retinae recorded at each age were as follows: $\mathrm{P} 11-\mathrm{P} 12, n=3$; $\mathrm{P} 13-\mathrm{P} 14, n=3$; P15-P19, $n=3$; and P19-P22, $n=6$. We found that evoked responses in the ganglion cell layer can be elicited beginning from P13 but not in younger P11 retinae, even though 
$\mathrm{P} 11$
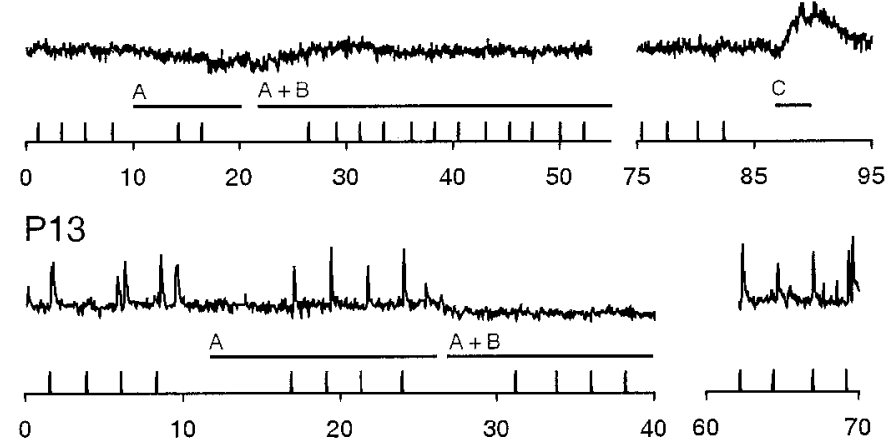

P15

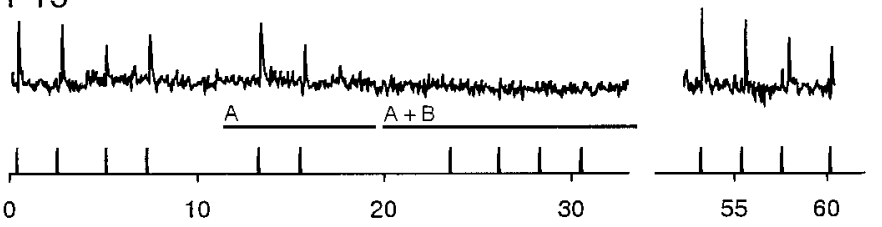

P21

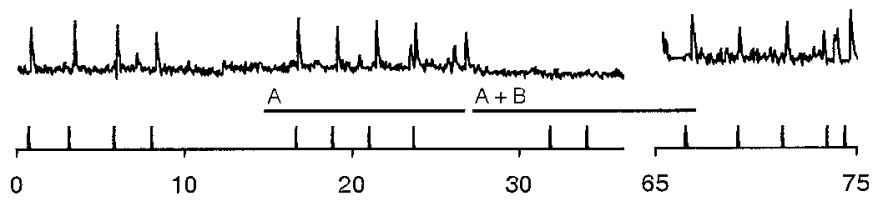

Time (min)

Figure 8. Maturation of the bipolar-to-ganglion cell communication as assessed by evoked responses in RGCs at various ages. Bipolar cells were stimulated by local puffs of $\mathrm{K}^{+}$as $\left[\mathrm{Ca}^{2+}\right]_{\mathrm{i}}$ in ganglion cells within the field of view was monitored as described in Figure 7. Vertical marks on the time axis indicate when a puff was delivered, and the traces above each axis reveal the changes in $\left[\mathrm{Ca}^{2+}\right]_{\mathrm{i}}$ of a nearby ganglion cell. To ensure that we maximized glutamatergic excitation to the ganglion cell, we abolished inhibition by bathing the slice in picrotoxin $(100 \mu \mathrm{M})$ and strychnine $(5$ $\mu \mathrm{M}$ ) (solution $A$; indicated by horizontal bars). The glutamatergic nature of the response in the ganglion cells was confirmed by the elimination of evoked responses in the presence of APV $(100 \mu \mathrm{M})$ and NBQX $(10 \mu \mathrm{M})$ (solution $B$ ). The ability to generate evoked responses resumed after washout of the glutamatergic antagonists. The inability to evoke a response in ganglion cells at P11 was unlikely to be caused by an insensitivity to glutamate because application of glutamate $(100 \mu \mathrm{M}$; horizontal bar C) produced an increase in $\left[\mathrm{Ca}^{2+}\right]_{\mathrm{i}}$.

ganglion cells at this age were responsive to direct applications of exogenous glutamate (Fig. 8). The glutamatergic nature of the transmission of the bipolar-to-ganglion cell connection was confirmed by the ability of NBQX and APV to block reversibly the evoked responses in the ganglion cell and inner nuclear layers.

These observations suggest that bipolar cells can provide functional glutamatergic drive to retinal ganglion cells and amacrine cells beginning around P13. This result is consistent with the interpretation that the increasing dependence of spontaneous bursting in ganglion cells on glutamatergic transmission during neonatal development occurs as the functional glutamatergic drive from bipolar cells to ganglion cells develops and matures.

\section{Effects of APB on bursting activity of On and Off ganglion cells}

To implicate further the role of endogenous glutamatergic signaling from bipolar cells in driving spontaneous bursting activity in ganglion cells, we examined ganglion cell activity using an intervention that suppresses endogenous bipolar activity. The metabotropic glutamate receptor mGluR6, which binds to the agonist APB, is expressed in On bipolar cells and localized to its dendrites but is not expressed at all in Off bipolar cells (Nomura et al., 1994; Ueda et al., 1997). In the absence of light stimulation, On bipolar cells are hyperpolarized by glutamate via activation of APB-sensitive mGluR6 receptors on these cells. By contrast, Off bipolar cells, lacking the APB-sensitive receptors, are depolarized after activation of ionotropic glutamate receptors (Slaughter and Miller, 1981; Nawy and Jahr, 1990; de la Villa et al., 1995). Thus, the application of APB to older P20-P23 retinae will suppress endogenous glutamatergic drive originating from the On bipolar cells but not that from Off bipolar cells. By measuring spontaneous bursting activity in On and Off ganglion cells in the presence of $\mathrm{APB}$, we were able to examine the role of endogenous bipolar signaling in driving bursting activity.

Figure 9 shows the effects of APB on the activity patterns of On and Off RGCs in a P21 retina at the age when glutamatergic transmission is absolutely required for spontaneous bursting activity in the ganglion cells. Putative On and Off ganglion cells were classified according to their relative burst rates and by their dendritic stratification patterns after intracellular dye filling (Wong and Oakley, 1996). To reveal the effects of APB on bipolar cells, we first removed inhibition by GABA and glycine from amacrine cells using the antagonists bicuculline and strychnine. As demonstrated previously (Fischer et al., 1998), On cells showed a marked increase in bursting rates after disinhibition (Fig. 9A). Subsequently, when APB was applied, the activity in On ganglion cells was abolished, whereas that in Off cells persisted. These results are confirmed by the quantification of the data from recordings from several retinae (Fig. 9B). This preferential total suppression of bursting activity in On ganglion cells by the hyperpolarization of On bipolar cells indicates that in the On pathway at least, endogenous synaptic drive from bipolar cells is absolutely required for bursting activity in ganglion cells after the formation of functional bipolar-to-ganglion cell connections.

\section{DISCUSSION}

\section{Neurotransmitter control of spontaneous activity during development}

In this study, we demonstrate that the regulation of synchronized spontaneous activity in the ferret retina undergoes progressive change as the retina develops. Taken together with previous work, the results in this study enable us to put together a more unified picture of how patterned spontaneous activity is regulated in the developing ferret retina (Burgi and Grzywacz, 1994; Feller et al., 1997; Fischer et al., 1998; Butts et al., 1999). In the early phase of development, during the first 2 postnatal weeks, ganglion cells receive synaptic input primarily from a lateral network of amacrine cells (Fig. 10A). These amacrine cells drive spontaneous correlated bursting in ganglion cells using excitatory GABAergic (Fischer et al., 1998) and cholinergic (Feller et al., 1996) transmission. As glutamatergic bipolar cells are introduced into the retinal circuitry late in the second postnatal week and make initial contact with ganglion cells, excitatory glutamatergic transmission becomes increasingly important in driving spontaneous bursting in ganglion cells, whereas cholinergic transmission diminishes in importance. It is also at this stage that GABAergic transmission from amacrine cells switches from depolarizing to hyperpolarizing and begins to exert an inhibitory modulatory influence on spontaneous bursting (Fischer et al., 1998). These changing ef- 
A

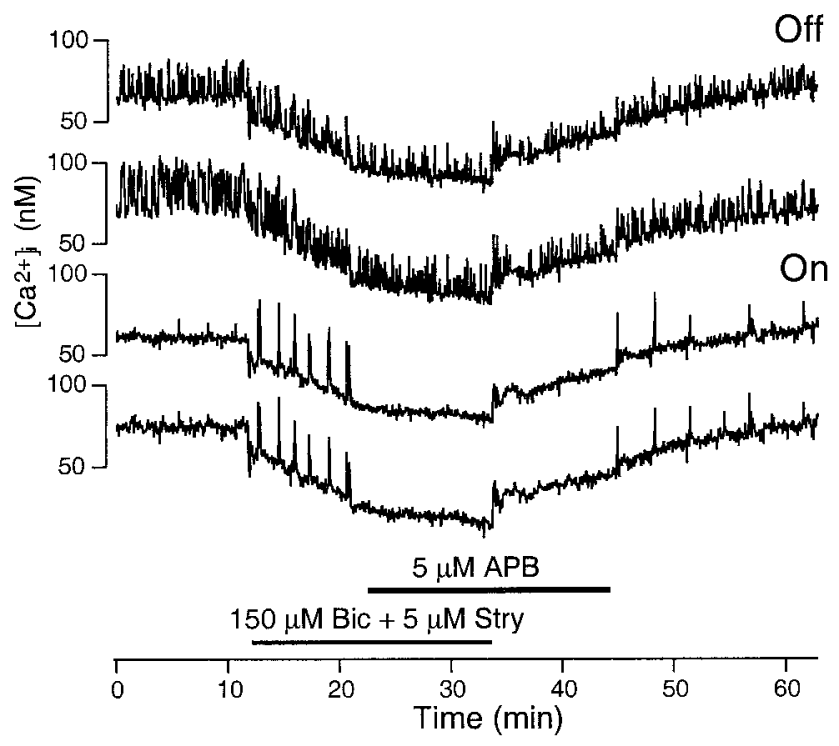

B

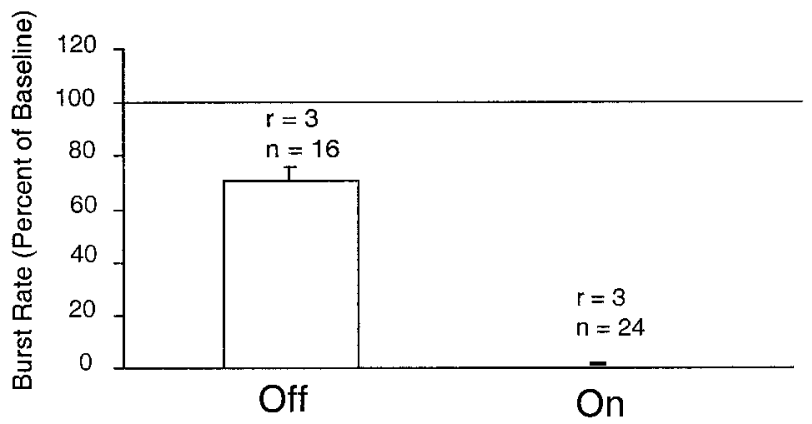

Figure 9. Effect of APB on On and Off ganglion cell activity in the absence of GABAergic and glycinergic inhibition as evaluated with calcium imaging. A, Application of APB (indicated by horizontal bar) abolishes bursting activity in On ganglion cells but not Off ganglion cells in P21 retina. Bursting activity recovers after the washout of APB. B, Quantitative summary of the effect of APB in On and Off ganglion cells in P17-P22 retinae is shown. Burst rates in APB are expressed as a percentage of the rate calculated for the period immediately preceding the application of APB under conditions of GABAergic and glycinergic blockade. APB reduced the burst rate in Off ganglion cells but preferentially abolished bursting altogether in On ganglion cells. These effects were statistically significant (Mann-Whitney $U$ test, $p<0.001 ; r=$ number of recordings; $n=$ number of cells monitored). Bic, Bicuculline; Stry, strychnine.

fects of glutamate, acetylcholine, and GABA on regulating spontaneous bursting activity are represented in Figure $10 \mathrm{~B}$. Thus, the overall mechanism seems to be one in which patterned spontaneous bursting is regulated by various forms of neurotransmission acting in an additive and coordinated manner (see Sernagor and Grzywacz, 1999). These regulatory effects change during development to accommodate new elements of retinal circuitry as they are added, to sustain a continuous and relevant output to retinal targets in the brain where retinogeniculate connections continue to be refined.

What are the actual retinal connections responsible for neurotransmitter regulation of spontaneous activity? In the earlier developmental period, at P7-P8, spontaneous bursting is driven additively by glutamate, acetylcholine, and GABA. Although cholinergic and GABAergic amacrine-to-ganglion cell connec-
A

A

P7

P20

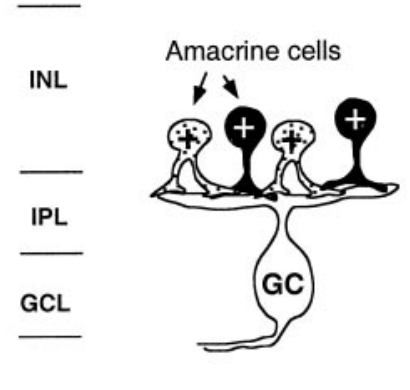

Amacrine cells

(2) ACh GABA

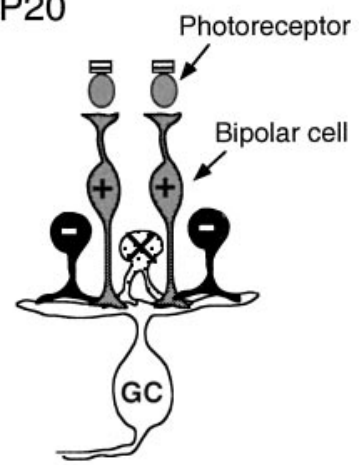

B
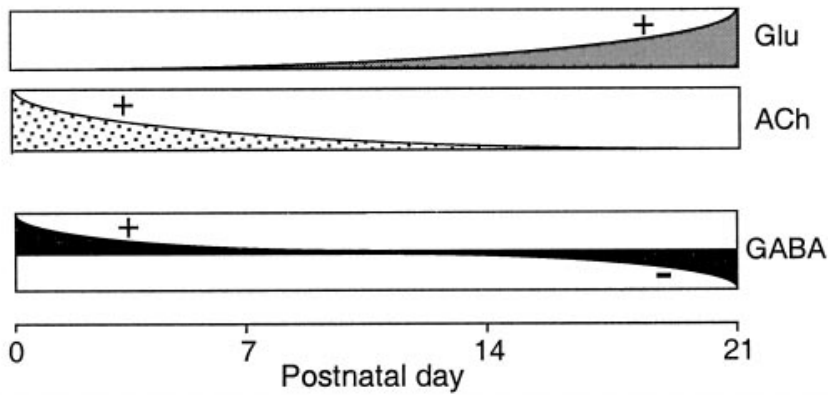

Figure 10. Changing effects of neurotransmission on spontaneous rhythmic bursting in RGCs. $A$, Forms of neurotransmission from presynaptic cells and their effects on spontaneous activity in ganglion cells at P7 and at P20 (+, excitation; -, inhibition; $X$, nonparticipating via nicotinic receptors). $B$, Schematic showing developmental changes in the effect of glutamatergic, cholinergic, and GABAergic neurotransmission on the spontaneous bursting activity. $G C, \mathrm{RGC}$; $G C L$, ganglion cell layer; $I N L$, inner nuclear layer.

tions have been documented at this time (Greiner and Weidman, 1981), the source of glutamate at this stage is less clear. The absence of bipolar synapses at this time raises the possibility that glutamate may be secreted in a paracrine manner by ventricular cells or precursors to bipolar cells (Pow et al., 1994). Alternatively, potential transient connections between immature glutamatergic photoreceptors, observed to extend synaptophysinpositive processes into the IPL at this stage, may act as a source of glutamatergic transmission (Johnson et al., 1999). The additive nature of glutamatergic and cholinergic drives at this early stage also suggests that glutamate, at least in part, exerts a direct effect on ganglion cells, as opposed to acting solely via intermediate cholinergic cells presynaptic to the ganglion cells. At the later stage, at P17-P23, when endogenous glutamatergic drive from bipolar cells becomes essential for spontaneous activity, the waning of cholinergic nicotinic regulation indicates that glutamatergic excitation must also occur directly onto ganglion cells. However, despite the decrease in cholinergic nicotinic drive at this stage, it is unlikely that a dismantling of connections from cholinergic amacrine cells to ganglion cells occurs because these connections are present at maturity, subserving important functions in adult vision (Vaney, 1990; Peters and Masland, 1996; He and Masland, 1997). 
Developmental changes in the neurotransmitter regulation of spontaneous activity have also been observed in the retina of the embryonic chick (Sernagor and O'Donovan, 1997; Catsicas et al., 1998; Wong et al., 1998), as well as in other developing systems, such as in the hippocampus (Garaschuk et al., 1998) and spinal cord (Chub and O’Donovan, 1998; Milner and Landmesser, 1999). It is possible that conserved mechanisms exist in which excitatory cholinergic and GABAergic circuits are first assembled and then followed by the subsequent introduction of glutamatergic connections, coinciding with the excitatory-to-inhibitory reversal of GABAergic transmission (Ben Ari et al., 1997; Leinekugel et al., 1997). The changing regulatory control of spontaneous activity described here may be a reflection of the developmental rules by which many neuronal circuits are assembled at each stage. Lastly, other modes of transmission such as those mediated via muscarinic receptors may also impinge on the regulation of spontaneous bursting (Zhou and Zhao, 1999).

\section{Mechanisms generating diversity in spontaneous activity patterns}

In the early stage of development, before bipolar synaptogenesis, spontaneous activity propagates across the retina in the form of waves, with RGCs of all classes sharing a uniform activity pattern. The spatial and temporal features of this patterned activity are thought to contain information necessary to refine the connectivity of ganglion cell arbors in the lateral geniculate nucleus, namely, the segregation of RGC arbors into eye-specific laminae and the refinement of retinotopic maps (Wong, 1999). However, later in development, at the time of bipolar synaptogenesis, a diversification in bursting rhythms develops between neighboring cells; ganglion cells belonging to the On and Off subclasses begin to display two sets of distinct bursting rhythms (Wong and Oakley, 1996). The development of this difference in patterned activity is suitable for directing the activity-dependent segregation (Hahm et al., 1991, 1999; Cramer and Sur, 1997) of On and Off ganglion cell arbors into separate geniculate sublaminae occurring at this time (Lee and Wong, 1996; Miller, 1996).

What mechanisms in the retina give rise to these distinct Onand Off-specific activity patterns at the later stage in development? Previous work in this laboratory has demonstrated that GABAergic transmission can differentially modulate bursting in On and Off cells by suppressing On cells to a larger extent than Off cells (Fischer et al., 1998). However, our previous and present studies show that the disparity in bursting rates of On and Off ganglion cells, although reduced, still persists in the absence of GABAergic and glycinergic signaling (see Fig. 9A). Because cholinergic blockade does not affect bursting patterns significantly at this stage, these On- and Off-specific rhythms are likely to be driven by glutamatergic transmission. In addition, glutamatergic bipolar cells, which are differentiated into On and Off subclasses (Miller et al., 1999), begin to make synaptic contact with ganglion cells at approximately the same time that diverse bursting rhythms emerge (Greiner and Weidman, 1981), further implicating the role of bipolar signaling in generating On and Off rhythms.

How can glutamatergic bipolar transmission confer distinct bursting rhythms in On and Off ganglion cells? Our observation that APB abolishes spontaneous bursting in On ganglion cells but not in Off ganglion cells (Fig. 9) indicates that On and Off bipolar cells are likely to provide separate glutamatergic drives onto On and Off ganglion cells, respectively, by the third postnatal week. It also suggests that the distinct bursting rates in On versus Off ganglion cells may result from differences in the amount of glutamatergic drive originating from On versus Off bipolar cells, respectively. This potential disparity between afferent On versus Off bipolar drives may arise from intrinsic differences between these cells; alternatively, they may be caused by differences in the response of On and Off bipolar cells to endogenous glutamate release from immature photoreceptors in the outer plexiform layer (OPL). Although the outer segments of photoreceptors are immature and the retina is still unresponsive to ambient light at this stage, glutamatergic ribbon synapses of photoreceptors are already present in the OPL (Greiner and Weidman, 1981) and may be capable of driving postsynaptic bipolar cells. As such, glutamatergic signaling onto On bipolar cells through the mGluR6 receptor would hyperpolarize these cells. By contrast, Off bipolar cells, which lack the mGluR6 receptor altogether, will be depolarized by glutamate released in the OPL. As a result, On bipolar cells may produce a smaller synaptic output relative to Off bipolar cells, resulting in a relatively lower bursting rate in On ganglion cells. Although maturation of the glutamatergic pathway appears to contribute to diversification of On and Off rhythms, changes in the intrinsic physiological properties of ganglion cells also need to be considered (Wang et al., 1997).

Our results also show that although Off ganglion cell activity persists in the presence of APB, it is slightly reduced from that in the controls (Fig. 9B), indicating that APB does not affect On ganglion cell bursting solely. It is possible that APB may exert direct effects on ganglion cells via metabotropic glutamate receptors in addition to mGluR6 (Duvoisin et al., 1995). Other studies however have suggested that these direct effects may be small (Liets and Chalupa, 1996). In addition, rod bipolar cells, which are also hyperpolarized by APB, may exert an indirect effect on Off ganglion cells via AII amacrine cells (Kolb and Famiglietti, 1974; McGuire et al., 1984) that form inhibitory glycinergic inputs onto Off ganglion cells. Indeed, the application of APB to mature retina has been found to increase the maintained discharge in Off ganglion cells, while decreasing that in On ganglion cells (Bolz et al., 1984). In the present study, we performed our APB experiments under conditions of glycinergic blockade that eliminate the indirect contribution of rod bipolar cells to spontaneous activity in ganglion cells. As such, the effects of APB on ganglion cell activity described here are unlikely to arise from the hyperpolarization of rod bipolars. Therefore, despite the possibility of additional loci for APB effects, we believe that the observed differences in APB response between On and Off ganglion cells are attributable primarily to a differential response on the part of On and Off cone bipolar cells.

Chronic in vivo applications of APB have been demonstrated to result in structural changes in the dendrites of developing ganglion cells (Bodnarenko and Chalupa, 1993; Bodnarenko et al., 1995; Bisti et al., 1998). Thus, an intriguing question that remains is how spontaneous activity driven by On and Off bipolar signaling contributes not only to the activity-dependent remodeling of the axonal terminals of the On and Off ganglion cells but also to the shaping of the dendritic arbors of these ganglion cells.

\section{REFERENCES}

Baldridge WH (1996) Optical recordings of the effects of cholinergic ligands on neurons in the ganglion cell layer of mammalian retina. J Neurosci 16:5060-5072.

Ben Ari Y, Khazipov R, Leinekugel X, Caillard O, Gaiarsa JL (1997) $\mathrm{GABA}_{\mathrm{A}}, \mathrm{NMDA}$ and AMPA receptors: a developmentally regulated "menage a trois." Trends Neurosci 20:523-529. 
Bisti S, Gargini C, Chalupa LM (1998) Blockade of glutamate-mediated activity in the developing retina perturbs the functional segregation of ON and OFF pathways. J Neurosci 18:5019-5025.

Bodnarenko SR, Chalupa LM (1993) Stratification of ON and OFF ganglion cell dendrites depends on glutamate-mediated afferent activity in the developing retina. Nature 364:144-146.

Bodnarenko SR, Jeyarasasingam G, Chalupa LM (1995) Development and regulation of dendritic stratification in retinal ganglion cells by glutamate-mediated afferent activity. J Neurosci 15:7037-7045.

Burgi PY, Grzywacz NM (1994) Model for the pharmacological basis of spontaneous synchronous activity in developing retinas. J Neurosci 14:7426-7439.

Butts DA, Feller MB, Shatz CJ, Rokhsar DS (1999) Retinal waves are governed by collective network properties. J Neurosci 19:3580-3593.

Catsicas M, Bonness V, Becker D, Mobbs P (1998) Spontaneous Ca ${ }^{2+}$ transients and their transmission in the developing chick retina. Curr Biol 8:283-286.

Chub N, O’Donovan MJ (1998) Blockade and recovery of spontaneous rhythmic activity after application of neurotransmitter antagonists to spinal networks of the chick embryo. J Neurosci 18:294-306.

Cramer KS, Sur M (1997) Blockade of afferent impulse activity disrupts on/off sublamination in the ferret lateral geniculate nucleus. Brain Res Dev Brain Res 98:287-290.

de la Villa P, Kurahashi T, Kaneko A (1995) L-Glutamate-induced responses and cGMP-activated channels in three subtypes of retinal bipolar cells dissociated from the cat. J Neurosci 15:3571-3582.

Duvoisin RM, Zhang C, Ramonell K (1995) A novel metabotropic glutamate receptor expressed in the retina and olfactory bulb. J Neurosci 15:3075-3083.

Feller MB (1999) Spontaneous correlated activity in developing neural circuits. Neuron 22:653-656.

Feller MB, Wellis DP, Stellwagen D, Werblin FS, Shatz CJ (1996) Requirement for cholinergic synaptic transmission in the propagation of spontaneous retinal waves. Science 272:1182-1187.

Feller MB, Butts DA, Aaron HL, Rokhsar DS, Shatz CJ (1997) Dynamic processes shape spatiotemporal properties of retinal waves. Neuron 19:293-306.

Fischer KF, Lukasiewicz PD, Wong ROL (1998) Age-dependent and cell class-specific modulation of retinal ganglion cell bursting activity by GABA. J Neurosci 18:3767-3778.

Galli L, Maffei L (1988) Spontaneous impulse activity of rat retinal ganglion cells in prenatal life. Science 242:90-91.

Garaschuk O, Hanse E, Konnerth A (1998) Developmental profile and synaptic origin of early network oscillations in the CA1 region of rat neonatal hippocampus. J Physiol (Lond) 507:219-236.

Greiner JV, Weidman TA (1981) Histogenesis of the ferret retina. Exp Eye Res 33:315-332.

Gummer AW, Mark RF (1994) Patterned neural activity in brain stem auditory areas of a prehearing mammal, the tammar wallaby (Macropus eugenii). NeuroReport 5:685-688.

Hahm JO, Langdon RB, Sur M (1991) Disruption of retinogeniculate afferent segregation by antagonists to NMDA receptors. Nature 351:568-570.

Hahm JO, Cramer KS, Sur M (1999) Pattern formation by retinal afferents in the ferret lateral geniculate nucleus: developmental segregation and the role of $N$-methyl-D-aspartate receptors. J Comp Neurol 411:327-345.

He S, Masland RH (1997) Retinal direction selectivity after targeted laser ablation of starburst amacrine cells. Nature 389:378-382.

Johnson PT, Williams RR, Cusato K, Reese BE (1999) Rods and cones project to the inner plexiform layer during development. J Comp Neurol 414:1-12.

Katz LC, Shatz CJ (1996) Synaptic activity and the construction of cortical circuits. Science 274:1133-1138.

Kolb H, Famiglietti EV (1974) Rod and cone pathways in the inner plexiform layer of cat retina. Science 186:47-49.

Lee CW, Wong ROL (1996) Developmental patterns of On/Off retinal ganglion cell activity lead to segregation of their afferents under a Hebbian synaptic rule. Soc Neurosci Abstr 22:1202.

Leinekugel X, Medina I, Khalilov I, Ben Ari Y, Khazipov R (1997) $\mathrm{Ca}^{2+}$ oscillations mediated by the synergistic excitatory actions of $\mathrm{GABA}_{\mathrm{A}}$ and NMDA receptors in the neonatal hippocampus. Neuron $18: 243-255$.

Liets LC, Chalupa LM (1996) The metabotropic glutamate agonist 2-amino-4-phosphonobutyric acid (APB) does not activate currents in postnatal retinal ganglion cells. NeuroReport 7:2873-2877.

Linden DC, Guillery RW, Cucchiaro J (1981) The dorsal lateral geniculate nucleus of the normal ferret and its postnatal development. J Comp Neurol 203:189-211.

Lukasiewicz PD, Roeder RC (1995) Evidence for glycine modulation of excitatory synaptic inputs to retinal ganglion cells. J Neurosci 15:4592-4601.

Masland RH (1977) Maturation of function in the developing rabbit retina. J Comp Neurol 175:275-286.

McCarthy M, Thomas L, Annand S, Bodnarenko SR (1998) NMDA receptor-mediated activity and the development of On and Off retinal ganglion cell (RGC) morphology. Soc Neurosci Abstr 24:1051.

McGuire BA, Stevens JK, Sterling P (1984) Microcircuitry of bipolar cells in cat retina. J Neurosci 4:2920-2938.

Meister M, Wong RO, Baylor DA, Shatz CJ (1991) Synchronous bursts of action potentials in ganglion cells of the developing mammalian retina. Science 252:939-943.

Miller ED, Wong WT, Wong ROL (1998) Developmental changes in the neurotransmitter regulation of correlated spontaneous retinal bursting activity. Soc Neurosci Abstr 24:812.

Miller ED, Tran M-N, Wong GK, Oakley DM, Wong ROL (1999) Morphological differentiation of bipolar cells in the ferret retina. Vis Neurosci, in press.

Miller KD (1996) Synaptic economics: competition and cooperation in synaptic plasticity. Neuron 17:371-374.

Milner LD, Landmesser LT (1999) Cholinergic and GABAergic inputs drive patterned spontaneous motoneuron activity before target contact. J Neurosci 19:3007-3022.

Nawy S, Jahr CE (1990) Suppression by glutamate of cGMP-activated conductance in retinal bipolar cells. Nature 346:269-271.

Nomura A, Shigemoto R, Nakamura Y, Okamoto N, Mizuno N, Nakanishi S (1994) Developmentally regulated postsynaptic localization of a metabotropic glutamate receptor in rat rod bipolar cells. Cell 77:361-369.

O'Donovan MJ (1999) The origin of spontaneous activity in developing networks of the vertebrate nervous system. Curr Opin Neurobiol 9:94-104.

Penn AA, Riquelme PA, Feller MB, Shatz CJ (1998) Competition in retinogeniculate patterning driven by spontaneous activity. Science 279:2108-2112.

Peters BN, Masland RH (1996) Responses to light of starburst amacrine cells. J Neurophysiol 75:469-480.

Pow DV, Crook DK, Wong ROL (1994) Early appearance and transient expression of putative amino acid neurotransmitters and related molecules in the developing rabbit retina: an immunocytochemical study. Vis Neurosci 11:1115-1134.

Rapier C, Lunt GG, Wonnacott S (1990) Nicotinic modulation of $\left[{ }^{3} \mathrm{H}\right]$ dopamine release from striatal synaptosomes: pharmacological characterisation. J Neurochem 54:937-945.

Roerig B, Nelson DA, Katz LC (1997) Fast synaptic signaling by nicotinic acetylcholine and serotonin 5-HT3 receptors in developing visual cortex. J Neurosci 17:8353-8362.

Schwartz TH, Rabinowitz D, Unni V, Kumar VS, Smetters DK, Tsiola A, Yuste R (1998) Networks of coactive neurons in developing layer 1. Neuron 20:541-552.

Sernagor E, Grzywacz NM (1996) Influence of spontaneous activity and visual experience on developing retinal receptive fields. Curr Biol 6:1503-1508.

Sernagor E, Grzywacz NM (1999) Spontaneous activity in developing turtle retinal ganglion cells: pharmacological studies. J Neurosci 19:3874-3887.

Sernagor E, O'Donovan MJ (1997) Cellular mechanisms underlying retinal waves in the chick embryo. Soc Neurosci Abstr 23:306.

Slaughter MM, Miller RF (1981) 2-Amino-4-phosphonobutyric acid: a new pharmacological tool for retina research. Science 211:182-185.

Spitzer NC, Olson E, Gu X (1995) Spontaneous calcium transients regulate neuronal plasticity in developing neurons. J Neurobiol 26:316-324.

Ueda Y, Iwakabe H, Masu M, Suzuki M, Nakanishi S (1997) The mGluR6 5' upstream transgene sequence directs a cell-specific and developmentally regulated expression in retinal rod and ON-type cone bipolar cells. J Neurosci 17:3014-3023.

Vaney DI (1990) The mosaic of amacrine cells in the mammalian retina. Prog Retin Res 9:49-100. 
Varanda WA, Aracava Y, Sherby SM, VanMeter WG, Eldefrawi ME, Albuquerque EX (1985) The acetylcholine receptor of the neuromuscular junction recognizes mecamylamine as a noncompetitive antagonist. Mol Pharmacol 28:128-137.

Wang GY, Ratto G, Bisti S, Chalupa LM (1997) Functional development of intrinsic properties in ganglion cells of the mammalian retina. J Neurophysiol 78:2895-2903.

Wong ROL (1995a) Cholinergic regulation of $\left[\mathrm{Ca}^{2+}\right]_{\mathrm{i}}$ during cell division and differentiation in the mammalian retina. J Neurosci 15:2696-2706.

Wong ROL (1995b) Effects of glutamate and its analogs on intracellular calcium levels in the developing retina. Vis Neurosci 12:907-917.

Wong ROL (1999) Retinal waves and visual system development. Annu Rev Neurosci 22:29-47.

Wong ROL, Oakley DM (1996) Changing patterns of spontaneous bursting activity of on and off retinal ganglion cells during development. Neuron 16:1087-1095.

Wong ROL, Meister M, Shatz CJ (1993) Transient period of correlated bursting activity during development of the mammalian retina. Neuron 11:923-938.

Wong ROL, Chernjavsky A, Smith SJ, Shatz CJ (1995) Early functional neural networks in the developing retina. Nature 374:716-718.

Wong WT, Sanes JR, Wong ROL (1998) Developmentally regulated spontaneous activity in the embryonic chick retina. J Neurosci 18:8839-8852.

Zhou ZJ (1998) Direct participation of starburst amacrine cells in spontaneous rhythmic activities in the developing mammalian retina. J Neurosci 18:4155-4165.

Zhou ZJ, Zhao D (1999) Age-dependent and receptor type-specific role of acetylcholine in spontaneous waves of retinal excitation. Soc Neurosci Abstr 24:1042. 